\title{
Impacts of dimethyl phthalate on the bacterial community and functions in black soils
}

\section{OPEN ACCESS}

Edited by:

Cheng Zhong,

Tianiin University of Science and

Technology, China

Reviewed by:

Sandra Kittelmann,

AgResearch Ltd, New Zealand

Christopher L. Hemme,

University of Oklahoma, USA

*Correspondence:

Zhi-Gang Wang,

Department of Biotechnology, Institute of Life Science and Agriculture and Forestry, Qiqihar University, Wenhua Street 42\#, Jianhua District, Qiqihar City, Heilongjiang Province, Qiqihar 161006, China

wzg1980830@sina.com; Ying Zhang,

Department of Environmental Science, Institute of Resources and Environment, Northeast Agricultural University, Mucai Street 59\#,

Xiangfang District, Harbin City, Heilongjiang Province, Harbin 150030 ,

China

zhangyinghr@hotmail.com

Specialty section:

This article was submitted to Microbiotechnology, Ecotoxicology and Bioremediation,

a section of the journal Frontiers in Microbiology

Received: 23 February 2015 Accepted: 18 April 2015 Published: 05 May 2015

Citation:

Wang Z-G, Hu Y-L, Xu W-H, Liu S, Hu $Y$ and Zhang $Y$ (2015) Impacts of dimethyl phthalate on the bacterial community and functions in black soils. Front. Microbiol. 6:405. doi: 10.3389/fmicb.2015.00405

\begin{abstract}
Zhi-Gang Wang ${ }^{1,2 *}$, Yun-Long Hu${ }^{1}$, Wei-Hui Xu ${ }^{1}$, Shuai Liu ${ }^{1}$, Ying $\mathrm{Hu}^{1}$ and Ying Zhang ${ }^{3 *}$
'Department of Biotechnology, Institute of Life Science and Agriculture and Forestry, Qiqihar University, Qiqihar, China, ${ }^{2}$ Department of Environmental Science and Engineering, Institute of Municipal Environment and Engineering, Harbin Industry University, Harbin, China, ${ }^{3}$ Department of Environmental Science, Institute of Resources and Environment, Northeast Agricultural University, Harbin, China
\end{abstract}

Dimethyl phthalate (DMP), a known endocrine disruptor and one of the phthalate esters (PAEs), is a ubiquitous pollutant. Its impacts on living organisms have aroused great concern. In this study, the impacts of DMP contamination on bacterial communities and functions were tested by using microcosm model in black soils. The results showed that the operational taxonomic unit (OTUs) richness and bacterial diversity were reduced by DMP contamination. The relative percentages of some genera associated with nitrogen metabolism were increased by DMP contamination, while the relative percentages of some other genera that were extremely beneficial to soil health were decreased by DMP contamination. Further, the relative percentages of some genera that possessed the capability to degrade DMP were increased by the DMP treatment at low concentrations $(5,10$, and $20 \mathrm{mg} / \mathrm{kg})$, but were decreased by the high concentration DMP treatment $(40 \mathrm{mg} / \mathrm{kg})$. Clearly, DMP contamination changed the bacterial community structure and disturbed the metabolic activity and functional diversity of the microbes in black soils. Our results suggest that DMP pollution can alter the metabolism and biodiversity of black soil microorganisms, thereby directly impact fertility and ecosystem functions.

Keywords: bacterial community, metabolic function, black soils, dimethyl phthalate (DMP), contamination, biodiversity

\section{Introduction}

Dimethyl phthalate (DMP) is commonly used as a plasticizer to impart flexibility to rigid polyvinylchloride (PVC) resins (Boonnorat et al., 2014). As one of the phthalate esters (PAEs), DMP is the most extensively used compound for manufacturing various consumer products, and the consumption of it is increasing continually (Fang et al., 2009; Prasad and Suresh, 2015) every year. Because DMP is conjugated into plastics, it can fall off plastic products and disperse in the ecosystem easily (Latini, 2005; Souza et al., 2014). Commonly, DMP can migrate into soils via irrigation and the application of pesticides and plastic films (Cartwright et al., 2000; Erythropel et al., 2012; Wang et al., 2014). Considering its mutagenicity, teratogenicity and carcinogenicity, both the United States Environmental Protection Agency and the China State Environmental Protection Administration have listed DMP as an environmental priority pollutant (Jin et al., 2013).

The black soils (Mollisols) in China are the one of three major black soil resources in the world (Liu et al., 2014a). They are extremely important for maintaining China's food security (Xu et al., 2010 ), because they contribute to about $14 \%$ of the total crop production and $40 \%$ of the total soybean yield in China. However, the studies showed that a serious pollution situation exists there 
by PAEs, and in which DMP was the most dominant one (Zhang et al., 2015).

Microbes and enzymes are the vital active components of soils. They contribute to ecosystem sustainability due to their cosmopolitan survival, massive efficient genetic pool, catabolic versatility and stress tolerance potential (Singh, 2015). Because they are highly sensitive to changes in soil conditions, they have been used to assess soil quality in contaminated soils (Jusselme et al., 2013; Yang et al., 2014). Recent work indicated that there is a predictive relationship between microbial traits and the ecosystem function of soils (Allison, 2012; Graham et al., 2014). Due to the increasing emphasis on sustainable fertility and the environmental benefits of healthy soils, it is extremely important to elucidate the effects of DMP contamination on soil microbes. However, few studies are available on the effects of DMP on black soils. This study evaluates the response of the bacterial community structure and function to DMP contamination in black soils with a microcosm model.

\section{Materials and Methods}

\section{Study Site and Soil Preparation}

The experiments were conducted in the greenhouses of northeast Agricultural University (Harbin, China). The time was in October, 2013, which was the season of soybean maturity. The location for the sample collection was at the Harbin Xiangfang farm $\left(45^{\circ} 41^{\prime} \mathrm{N}, 126^{\circ} 45^{\prime} \mathrm{E}\right)$ in the black soil zone. The soil samples were collected randomly from 10 tillage layers $(0-20 \mathrm{~cm})$ within an area of approximately $100 \mathrm{~m}^{2}$. No residual DMP was detected in these samples. The soil $\mathrm{pH}$ was measured using a $\mathrm{pH}$ meter after shaking the soil water suspension (1: $2.5 \mathrm{w} / \mathrm{v})$ for $30 \mathrm{~min}$. Soil cation exchange capacity (CEC) was determined using the ammonium acetate method (Wang et al., 2008). An analysis of the total organic carbon (TOC) was performed with the Total Organic Carbon Analyzer (TOC-V, Shimadzu Labs) coupled with a Solid Sample Module (model SSM-5000, Shimadzu Labs). Total nitrogen (TN) and total phosphorus (TP) were measured by the Element Analyzer (Vario EL, Elementar Analysen systeme, Hanau, Germany). Particle size distribution was analyzed by the Sedima4-12 (Soil Particle Size Analyzer, Ecotech Ecological Technology Ltd., Beijing, China). The basic properties of the black soils used in the experiment are shown in Table 1.

\section{Microcosm Set-up}

DMP (purity greater than 99.9\%) was obtained from the National Standard Material Standard Sample Information Center (Beijing, China). Acetone was used as a cosolvent and was purchased from Traditional Chinese Medicine (Beijing, China). A stock solution of DMP was prepared in acetone at a concentration of $1000 \mathrm{mg} / \mathrm{L}$ and stored in the dark at $4^{\circ} \mathrm{C}$.

The microcosm model was used for the study because microcosm is a valuable tool for studying the interactions between microorganisms and their soil environments (Caracciolo et al., 2013). The soil was moistened up to $80 \%$ of its maximum field water holding capacity and preincubated at $25^{\circ} \mathrm{C}$ for $7 \mathrm{~d}$. The stock DMP solution was added to the soil in different concentrations: Control (CK), $0 \mathrm{mg} / \mathrm{kg}$; DMP treatment
1 (DMP1), 5 mg/kg; DMP treatment 2 (DMP2), 10 mg/kg; DMP treatment 3 (DMP3), $20 \mathrm{mg} / \mathrm{kg}$; and DMP treatment 4 (DMP4), $40 \mathrm{mg} / \mathrm{kg}$. The same amount of acetone solution was added to the control soils because the DMP solution was made by acetone. Then, all samples were incubated in the air for $3 \mathrm{~h}$ to completely volatilize the acetone. The soil samples were weighed $(650 \mathrm{~g})$ and placed in $1 \mathrm{~L}$ pots $(12.2 \mathrm{~cm}$ height $\times 18 \mathrm{~cm}$ diameter $)$. Three pots were prepared for each microcosm sample. Soil moisture was maintained at approximately 30\% throughout the experimental period. The soils were incubated in the pots for $25 \mathrm{~d}$ in the dark at $25^{\circ} \mathrm{C} \pm 2{ }^{\circ} \mathrm{C}$ with $70 \pm 5 \%$ relative humidity. Three samples were taken out from each pot, and then mix them together for homogenization using Bead beater (Bio-Spec). For the analysis of microbial community, microbial DNA was extracted from the homogenized samples, which was collected only on the 25th d post-DMP treatment, and sequenced by Illumina-MiSeq sequencing. For the analysis of microbial functional diversity, the homogenized samples were analyzed by Biolog-ECO Plates. Four time points were selected for the incubation period, they were $0,5,10$, and $25 \mathrm{~d}$, respectively. For the analysis of soil enzyme activities, the homogenized samples were used to measure the activities of urease, protease, catalase, invertase, and polyphenol oxidase, which mediate $\mathrm{C}$ and $\mathrm{N}$ cycling in soil ecosystems, at 6 time points $(0,5,10,15,20$, and $25 \mathrm{~d}$ post-DMP treatment).

\section{DNA Extraction and Amplicon Generation}

Total DNA from soils was extracted ( $0.5 \mathrm{~g}$ wet weight) with the E.Z.N.A. Soil DNA Kit (Omega Bio-tek, Norcross, GA, U.S.) according to the manufacturer's instructions. The extracted DNA was diluted with TE buffer $(10 \mathrm{mM}$ Tris- $\mathrm{HCl}$ and $1 \mathrm{mM}$ EDTA, $\mathrm{pH}$ 8.0) and stored at $-20^{\circ} \mathrm{C}$ prior to use.

The V3-V4 region of the bacterial 16S ribosomal RNA gene was amplified by PCR using the following protocol: $95^{\circ} \mathrm{C}$ for $2 \mathrm{~min}$, followed by 25 cycles at $95^{\circ} \mathrm{C}$ for $30 \mathrm{~s}, 55^{\circ} \mathrm{C}$ for $30 \mathrm{~s}$, and $72^{\circ} \mathrm{C}$ for $30 \mathrm{~s}$, with a final extension at $72^{\circ} \mathrm{C}$ for $5 \mathrm{~min}$. The following primers were used to attach a barcode (an eight-base sequence unique to each sample): $338 \mathrm{~F}$ ( $5^{\prime}$-barcode-ATG CAG GGA CTA CHV GGG TWT CTA AT-3') and 806R (5'-ACT CCT ACG GGA GGC AGC A-3') (Kuczynski et al., 2012; Peiffer et al., 2013). PCR reactions were performed in triplicate in a $20 \mu \mathrm{L}$ mixture containing $4 \mu \mathrm{L}$ of $5 \times$ FastPfu Buffer, $2 \mu \mathrm{L}$ of $2.5 \mathrm{mM}$ dNTPs, $0.8 \mu \mathrm{L}$ of each primer $(5 \mu \mathrm{M}), 0.4 \mu \mathrm{L}$ of Fast$\mathrm{Pfu}$ polymerase, and $10 \mathrm{ng}$ of template DNA. Negative control samples were treated similarly but excluded the template DNA; these negative controls failed to produce visible PCR products.

\section{Illumina-MiSeq Sequencing and Processing of Sequencing Data}

After PCR process, DNA amplicons were purified with the Axy Prep DNA Gel Extraction Kit (Axygen Biosciences, Union City, CA, U.S.) and quantified using QuantiFluor ${ }^{\mathrm{TM}}$-ST (Promega, U. S.). Purified amplicons were pooled in equimolar ratios and paired-end sequenced $(2 \times 250)$ on an Illumina-MiSeq platform according to standard protocols.

Raw fastq files were demultiplexed and quality-filtered using QIIME (Quantitative Insights into Microbial Ecology, version 1.17) with the following criteria: $250 \mathrm{bp}$ reads were truncated 
where $N$ is the combined absorbance of all wells, $S$ is the number of wells with color changes, and $n_{i}$ is the absorbance of the ith well.

Here, index $H^{\prime}$ is used to estimate the microbial diversity, index $D$ is used to indicate the dominant microbial diversity, and index $E$ is used to show the microbial distribution uniformity, respectively (Juliet et al., 2002; Sala et al., 2006). A total of 31 carbon sources are included in each Biolog-ECO plate and they are classified into 6 major groups (amino acids, carbohydrates, polymers, esters, carboxylic acids and phenolic compounds) (Godoi et al., 2014). The differences on utilizing the carbon sources will reflect the changes on the soil microbial communities.

\section{Soil Enzyme Assays}

Urease was measured by the phenol sodium colorimetric method, and catalase was assessed by potassium permanganate titration (Yang et al., 2007). Protease was determined as reported by Ladd and Butler (Ladd and Butler, 1972). Invertase was determined using sucrose as the substrate (Guan, 1986). Polyphenol oxidase was measured according to the method of Saiya-Cork et al. (2002). All of the enzyme assays were performed in quadruplicate using two types of controls [i.e., substrate alone and soil-cocktail (everything but no substrate)].

\section{Statistical Analyses}

Software R (R Development Core Team, 2008) were used to calculate the percentage of classifiable reads and to generate the figures. Analyses of variance (ANOVA) and the least significant ranges test (Duncan's method) were performed with SPSS17.0 to test the significance $(p<0.05)$ of the differences among the treatments.

\section{Results}

\section{Response of Bacterial Community Structures and Biodiversity to DMP}

Illumina-MiSeq sequencing was applied to analyze the differences in microbial communities among the samples treated with DMP for 25 days. In order to analyze the microbial richness and diversity, a large number of reads (in the range of 22,825-29,011) were obtained for 16S rRNA gene amplicons of each sample, OTUs were derived, and then the $S_{\text {Chao } 1}$ and $H_{\text {shannon }}$ indices were calculated. The data were summarized in Table 2. As it was shown, the $S_{C h a o 1}$ and $H_{\text {shannon }}$ indices of the samples were declined with increasing DMP concentration.

A total of 326 genera were identified from these samples and used to study the bacterial community structures. Figure 1 shows that DMP treatment resulted in transformation of the bacterial community structure. Many bacterial genera with higher relative percentages were identified in black soils, such as Azohydromonas (4.89-19.22\%), Sphingomonas (5.47-7.56\%), Novosphingobium (2.80-5.76\%), Massilia (1.57-4.13\%), Arthrobacter (1.38-2.69\%), Flavisolibacter (1.34-2.52\%), Pseudomonas (0.94-4.41\%), Altererythrobacter (1.03-2.99\%), Flexibacter (1.00-1.77\%), Sphingobium (0.61-1.60\%), Adhaeribacter (0.70-1.35\%), Gemmatimonas
(0.90-1.25\%), Devosia (0.85-1.37\%), Thermomonas (0.79$1.29 \%)$, Pedobacter (0.54-1.24\%), Modestobacter (0.54-1.07\%), Microvirga (0.44-1.04\%), Aeromicrobium (0.51-1.11\%), Sphingopyxis (0.46-1.10\%), and Methylotenera (0.20-1.66\%). The changes on the relative percentages of Azohydromonas $\left(r^{2}=0.847^{*}, n=15\right)$, Microvirga $\left(r^{2}=0.921^{* *}\right.$, $n=15)$ and Methylotenera $\left(r^{2}=0.918^{* *}, n=15\right)$ were significant correlated with the DMP concentration. The relative percentages of Pseudomonas, Flexibacter, Thermomonas, Pedobacter, Flavobacterium, and Pontibacter were obviously reduced as the DMP concentration increased. Interestingly, the relative percentages of Novosphingobium, Massilia, Altererythrobacter, Sphingobium, Gemmatimonas, Modestobacter, Aeromicrobium, and Sphingopyxis were increased by the lower DMP concentrations (DMP1, DMP2, and DMP3), but were decreased by the highest DMP concentration (DMP4).

The PCoA results of the bacterial $\beta$-diversity analysis covered $74.55 \%$ (PC1, $p=0.0011)$ and $15.20 \%(\mathrm{PC} 2, p=0.0293)$ of the total changes of the microbial communities among the samples based on the Unweighted UniFrac distances (Figure 2). The clear changes in the $\beta$-diversity derived from this pattern occurred post-DMP exposure and increased with the increase in the DMP concentration. The PCoA revealed five separated clusters. Each cluster was distinguished due to the different DMP treatment. The analysis of $\beta$-diversity demonstrated that DMP exerted a significant effect on the community diversity.

\section{Response of Soil Microbial Functions to DMP Contamination}

The dynamic changes on the $A W C D$ (a), $H^{\prime}$ (b), $D$ (c), and $E$ (d) indices in the soils after DMP treatments were shown in Figures 3A-D. The microbial activities $(A W C D)$ were increased following the treatments with low concentration (DMP1 and DMP2), however, it was significantly decreased $(p<0.05)$ following the treatments with higher DMP concentration (DMP3 and DMP4) compared to the CK (Figure 3A). The microbial diversities ( $H^{\prime}$ indices) were not significantly changed in the treatments of DMP1 DMP2, and DMP3 compared to CK, but it was significantly reduced $(p<0.05)$ in DMP4 throughout the incubation period (Figure 3B). The dominant microbial diversities ( $D$ indices) were not significantly changed in DMP1 DMP2, and DMP3 compared to CK, but it was significantly reduced in DMP4 compared to $\mathrm{CK}$ throughout the incubation period (Figure 3C). The microbial distribution uniformities $(E$ indices) were decreased ( $p<0.05, r^{2}=0.683$ ) by the increases in the DMP concentration (Figure 3D).

Dynamic analyses were performed for the microbes from the soil samples by use of 6 groups of carbon sources in the BiologECO plates; the results were shown in Figure 4. The remarkable differences were observed by comparing the profiles of carbon utilization among the soil samples. The utilization of amino acids and carboxylic acids were significantly promoted by low DMP concentration (DMP1 and DMP2), and significantly inhibited by higher DMP concentration (DMP3 and DMP4) throughout the incubation period. The utilization of carbohydrates and phenolic compounds was promoted by low DMP concentration (DMP1, DMP2, and DMP3), and inhibited by DMP4 throughout the 
TABLE 2 | The comparisons of microbial community richness and $\alpha$-diversity for the five DMP treatments of soil microorganisms (CK, DMP1, DMP2, DMP3, DMP4) after 25 days incubation in the dark at $25^{\circ} \mathrm{C}$ and $70 \%$ relative humidity.

\begin{tabular}{|c|c|c|c|c|}
\hline Sample ID & Reads & OTUs $_{0.97}$ & $S_{\text {Chao1 }}$ & $H_{\text {Shannon }}$ \\
\hline CK & $26426 \pm 3547 a b$ & $1213 \pm 102 a$ & $38051 \pm 1258 a$ & $5.88 \pm 0.17 a$ \\
\hline DMP1 & $29011 \pm 2581 a$ & $1210 \pm 158 a$ & $31655 \pm 2361 b$ & $5.69 \pm 0.21 \mathrm{ab}$ \\
\hline DMP2 & $24164 \pm 3369 a b$ & $1175 \pm 208 a$ & $30811 \pm 3058 b$ & $5.62 \pm 0.11 b$ \\
\hline DMP3 & $26788 \pm 2978 a b$ & $1179 \pm 340 a$ & $29538 \pm 3947 b c$ & $5.53 \pm 0.24 b c$ \\
\hline DMP4 & $22825 \pm 3064 b$ & $1160 \pm 147 a$ & $26332 \pm 2845 c$ & $5.47 \pm 0.13 c$ \\
\hline
\end{tabular}

Different letters showing significant difference at $p=0.05$ using Waller Duncan test.

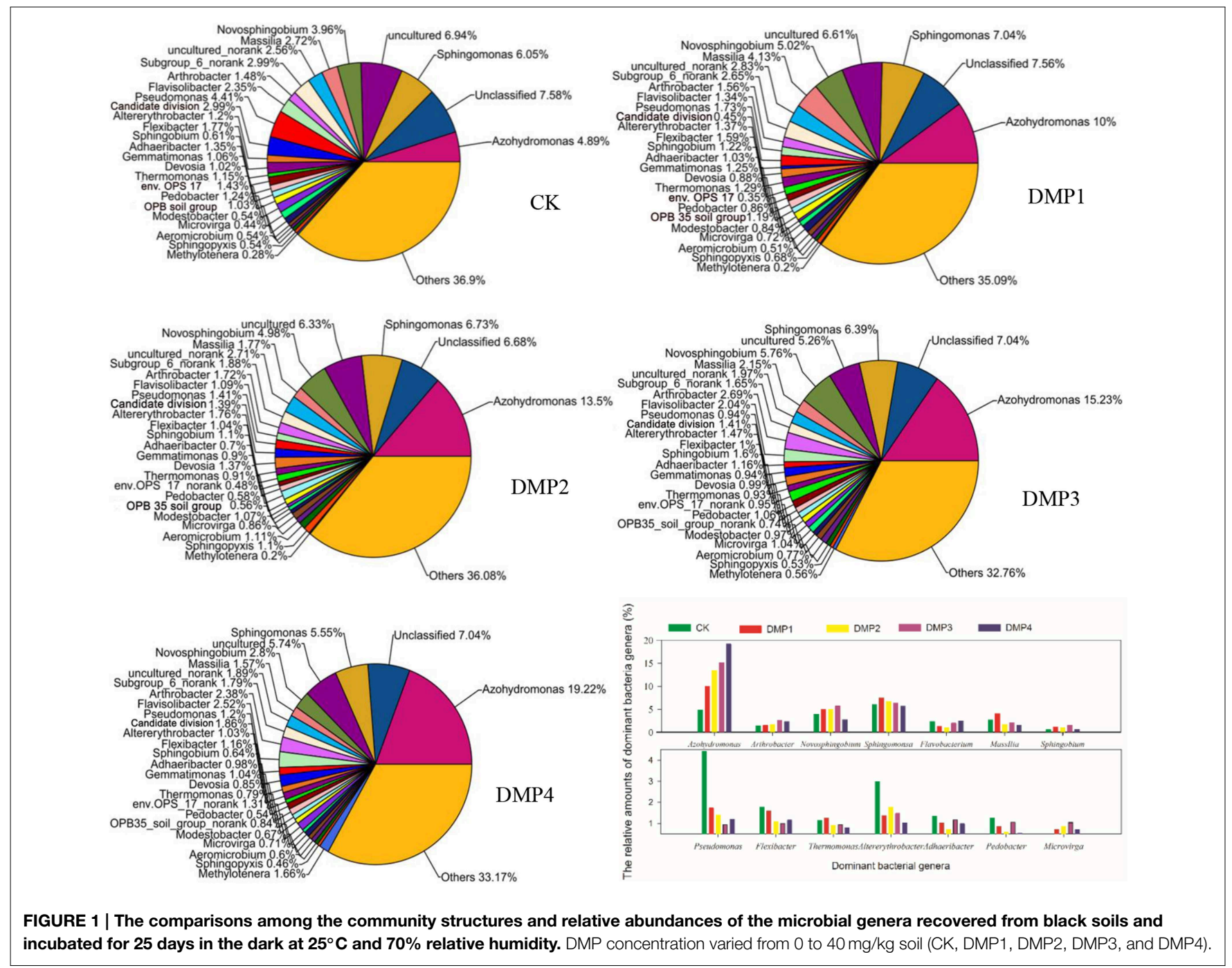

incubation period. The utilization of polymers was inhibited by low DMP concentration (DMP1 and DMP2), and promoted by higher DMP concentration (DMP3 and DMP4) at the beginning, and inhibited later. The utilization of ester was promoted by DMP treatments in a dosage-dependent manner, that is, it was correlated positively $\left(r^{2}=0.759^{*}, n=20\right)$ with the DMP concentration (Figure 4).

\section{Response of Soil Enzymes to DMP Contamination}

The dynamic changes in soil enzymes caused by DMP contamination throughout the incubation period were shown in Figures 5A-E. DMP significantly increased the activities of urease and invertase $\left(r^{2}=0.67^{*}\right.$ and $\left.r^{2}=0.59^{*}\right)$ within 25 days (Figures 5A,D). Conversely, the catalase activity was significantly 
inhibited $\left(r^{2}=0.75^{*}\right)$ by the increased DMP concentration (Figure 5C). Protease activity was increased by DMP at the beginning, but decreased in higher DMP concentration (DMP3 and DMP4) later (Figure 5B). Polyphenol oxidase activity was

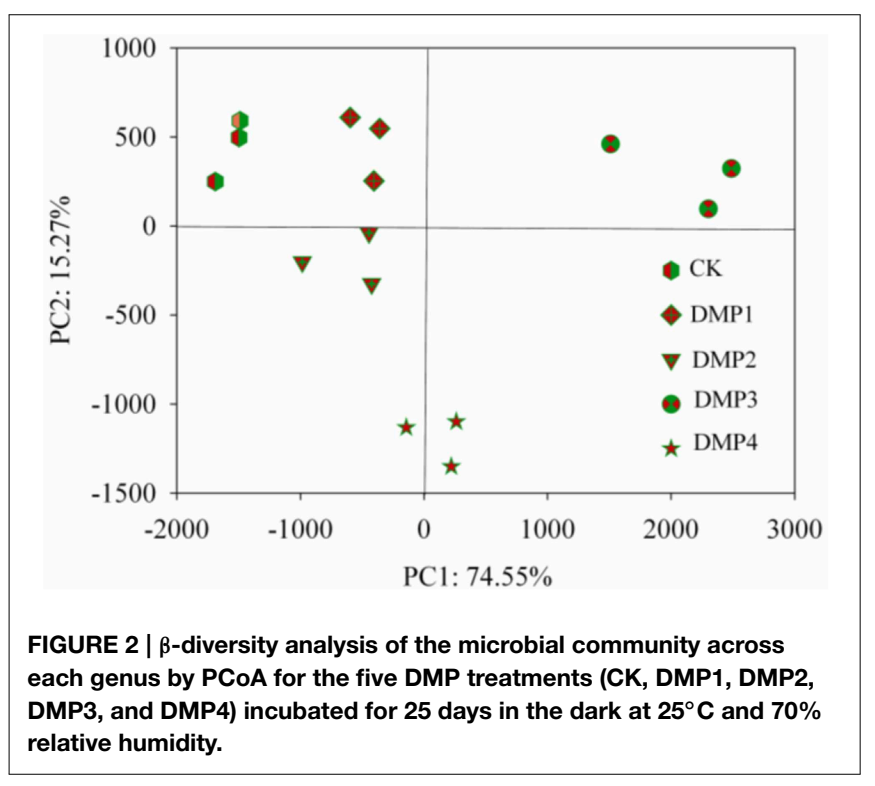

promoted by low DMP concentration (DMP1 and DMP2), but significantly inhibited by higher DMP concentration (DMP3 and DMP4) throughout the incubation period (Figure 5E).

\section{Discussion}

Microbes are the most important components of soils, and are a useful measure for soil health status and ecology. IlluminaMiSeq sequencing provides an unprecedented power for the deep understanding of bacterial community composition and diversity based on 16S rRNA gene libraries (de Gannes et al., 2013; Peiffer et al., 2013). Hence, the method was applied to analyze differences on microbial communities among the samples in this study. The results showed that the OTU richness and microbe diversity in black soils were gradually reduced by increasing DMP concentrations (Table 2). The results of this study basically correspond with the results obtained previously by Zhang et al. (2010), however, who only found polycyclic aromatic hydrocarbons (PAH) decreased the microbial richness and diversity in soil. But the effects of DMP were opposite to the effects of dioxins on soil microbial richness and diversity in (Hanano et al., 2014).

Additionally, it was observed that DMP treatments resulted in transformation of the microbial community (Figures 1, 2). All of the bacterial communities in the black soils were dominated by 21
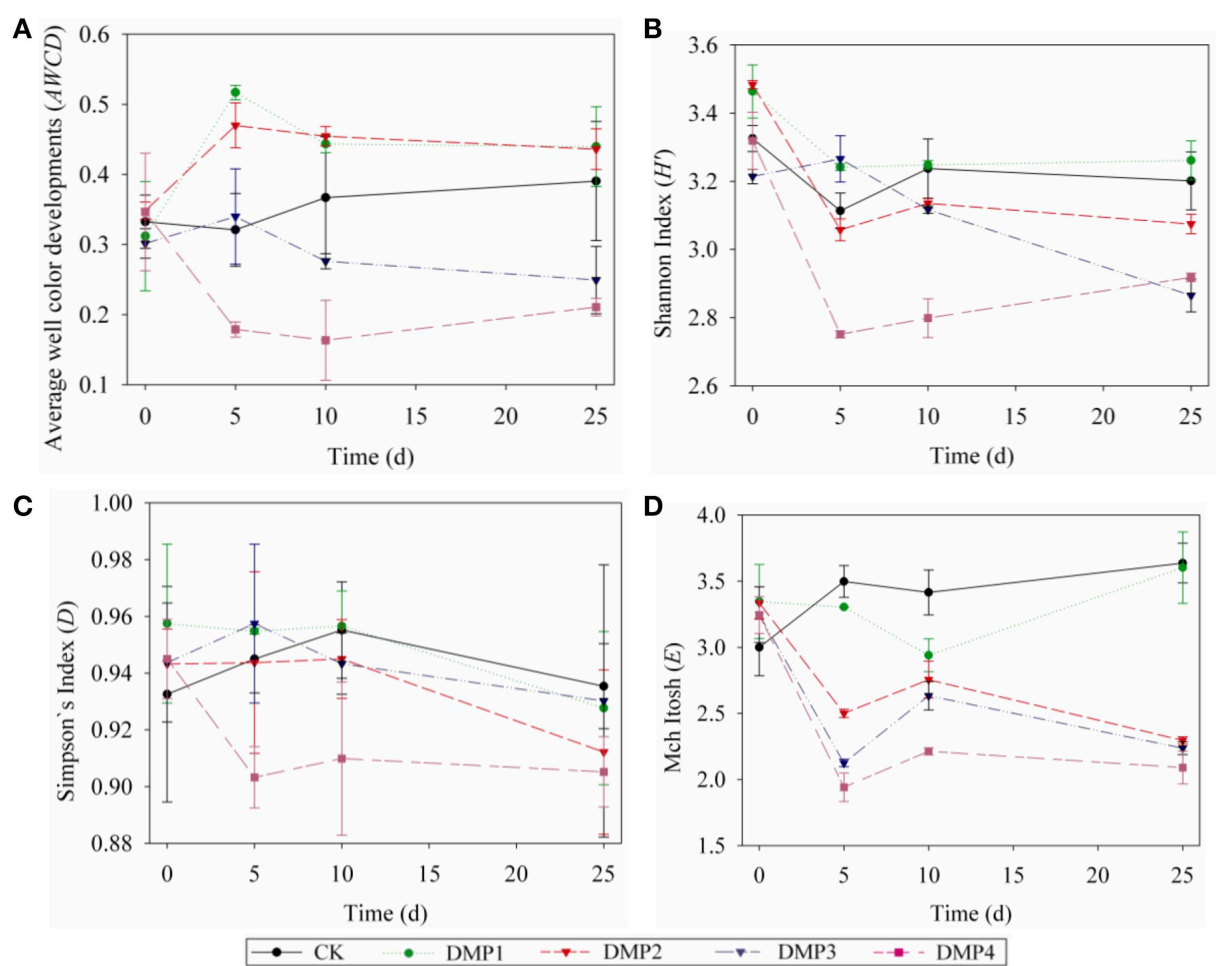

FIGURE 3 | The dynamic changes of bacterial activity and functional diversity on the microbial communities generated from the five DMP treatments (CK, DMP1, DMP2, DMP3, and DMP4) on black soil microorganisms within 25 days incubation in the dark at $25^{\circ} \mathrm{C}$ and $\mathbf{7 0} \%$ relative humidity. (A) Average well color development (AWCD); (B) $H^{\prime}$ index (Shannon index); (C) $D$ index (Simpson index); (D) $E$ index (Mclntosh index). The error bars indicate standard deviations $(n=3)$. 

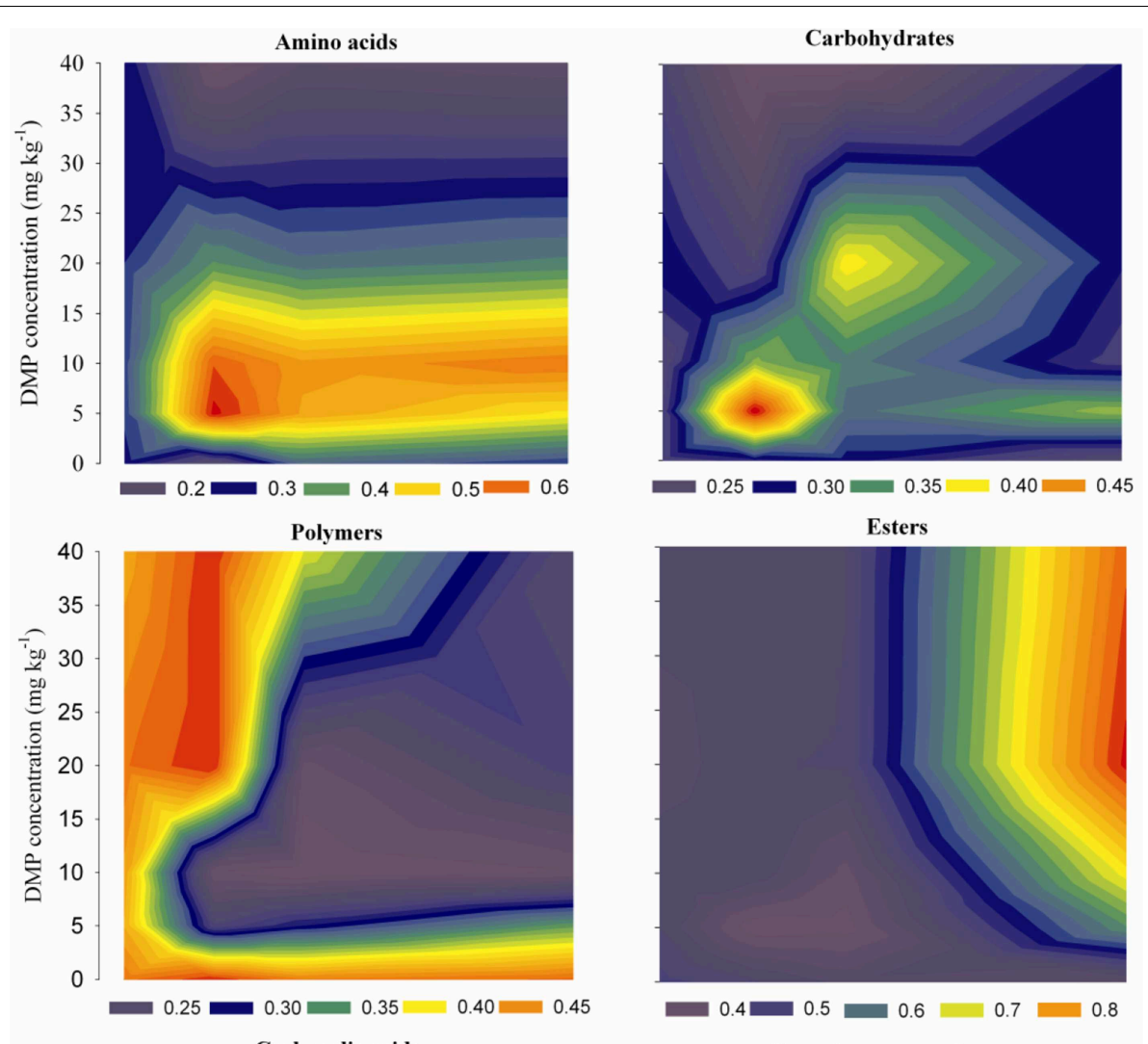

Esters
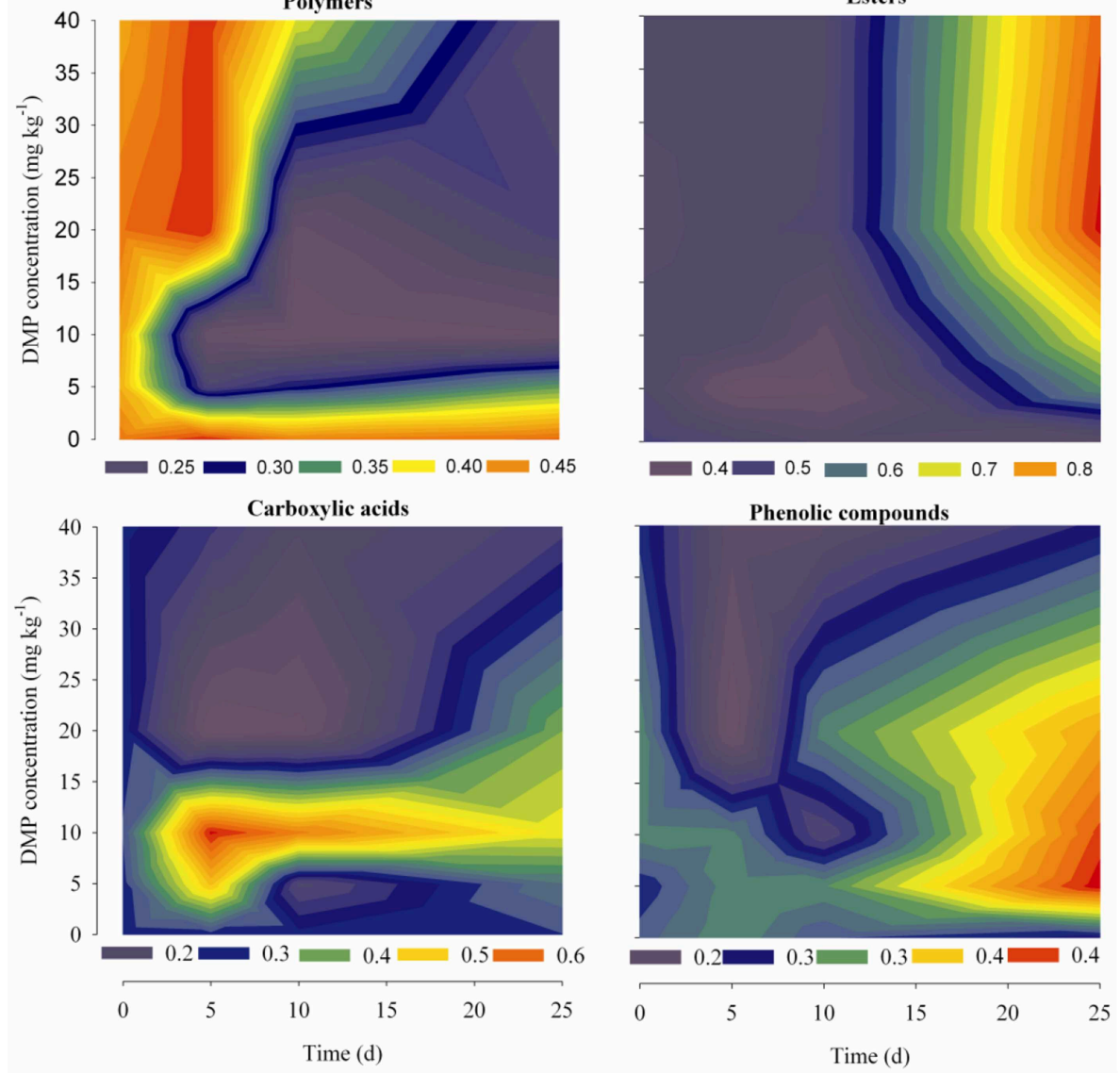

FIGURE 4 | The kinetic characteristics of carbon substrate utilization tested in Biolog-ECO plates for the five treatments (CK, DMP1, DMP2, DMP3, and DMP4) on black soil microorganisms incubated for 25 days in the dark at $25^{\circ} \mathrm{C}$ and $70 \%$ relative humidity.

major genera (the relative percentage must be $>0.2 \%)$. Although the total numbers of the major genera were not changed, but the relative percentages of the genera were altered by DMP contamination (Figure 1). Azohydromonas and Microvirga are key players in the nitrogen cycle in soils (Coelho et al., 2008; Ardley, 2012; Yousuf et al., 2014), and the relative percentages of Azohydromonas increased along with the increase in DMP concentration. The relative percentages of Microvirga increased along with the increase in lower DMP concentration, but dropped in the highest DMP concentration. The reason for the drop cannot be found at present. The relative percentages of Methylotenera increased along with the increase in DMP concentration, but the functions in soils for this bacterium are not clear. However, some genera that were distributed broadly in soils and have been shown to be beneficial to soil health were inhibited by increasing DMP concentration (Figure 1). These genera included Pseudomonas (Troxler et al., 2012; Dharni et al., 2014; Stelting et al., 2014), Flexibacter (Jones and Knowles, 

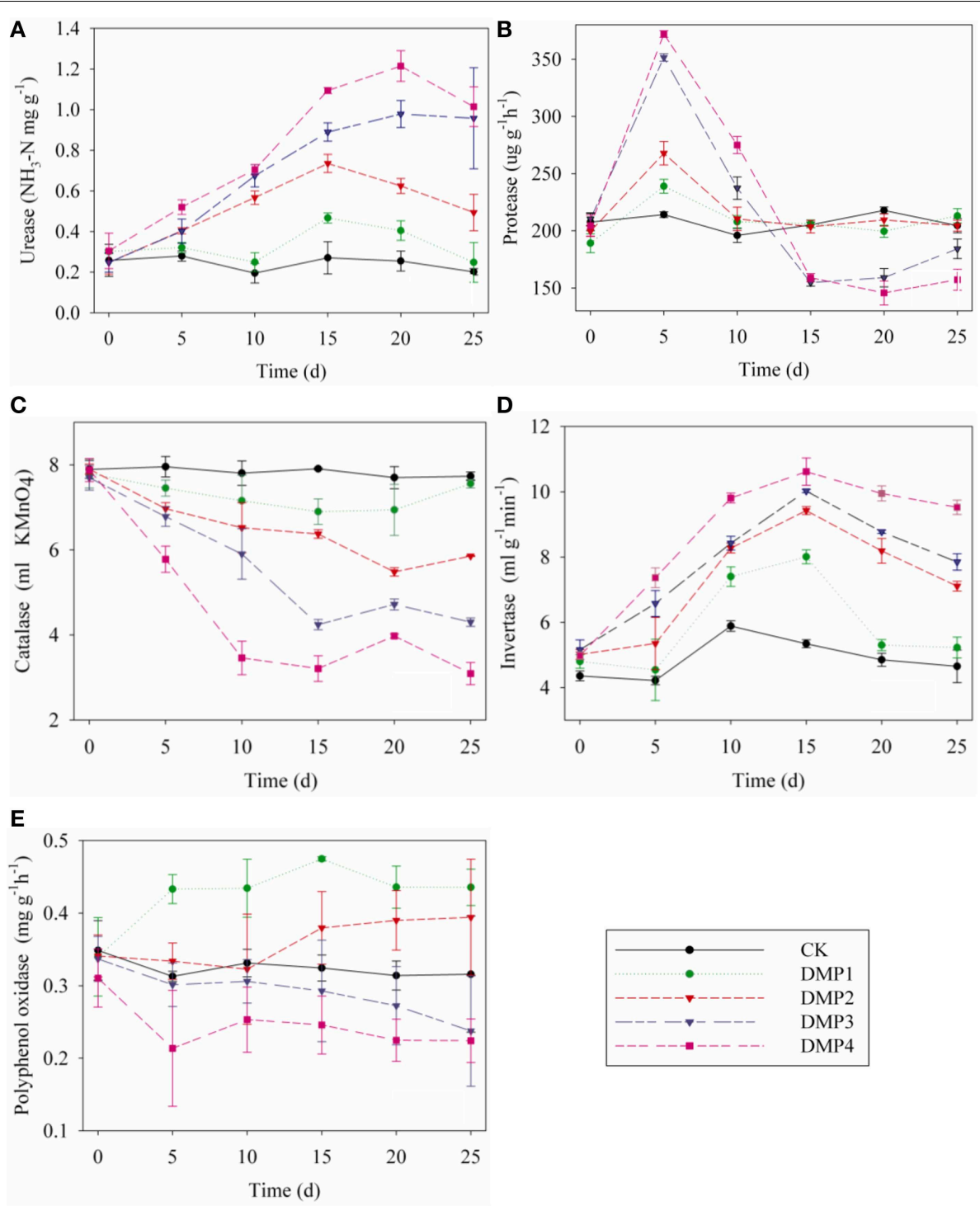

FIGURE 5 | Effects of DMP contamination on the enzyme activities from black soil microorganisms with 25 days incubation in the dark at $25^{\circ} \mathrm{C}$ and $70 \%$ relative humidity. DMP concentration varied from 0 to
$40 \mathrm{mg} / \mathrm{kg}$ soil (CK, DMP1, DMP2, DMP3, and DMP4). (A) Urease; (B) Protease; (C) Catalase; (D) Invertase; (E) Polyphenol Oxidase. The error bars indicate standard deviations $(n=3)$.
1991; Drijber and McGill, 1994), Devosia (Rivas et al., 2002; Ryu et al., 2008; Hassan et al., 2014), and Flavobacterium (Das et al., 2012; Kolton et al., 2014). The relative percentages of some genera increased by the lower DMP concentrations ( 5 , 10 , and $20 \mathrm{mg} / \mathrm{kg}$ ), but then they were inhibited by the high DMP concentration $(40 \mathrm{mg} / \mathrm{kg})$, such as the case in Microvirga (Figure 1). The genera observed to follow this trend showed to have a capability to degrade organic pollutants in soils, such as Novosphingobium (Yan et al., 2007; Saxena et al., 2013), Massilia (Faramarzi et al., 2009), Altererythrobacter (Dunlevy et al., 2013), Sphingobium (Cunliffel and Kertesz, 2006; Raina et al., 2008), and Sphingopyxis (Jindal et al., 2013). The results indicated DMP contamination could stimulate some genera that have resistance of DMP, and inhibit some genera that are damaged by DMP. The analysis by PCoA indicated that $\beta$-diversity was changed by DMP treatments (Figure 2). This may be due to the accumulation of DMP in the hydrophobic regions of the microbial membrane and the disruption of membrane fluidity (Cartwright et al., 2000), and finally inhibit the growth of some microbes.

The changes on the soil microbial community also were supported by the study of Biolog-Eco plate. The $A W C D$ value from the study of Biolog-Eco plate is commonly used as an indicator of the total metabolic activity of soil microbes (Wu et al., 2014). In this study, compared to the control, the $A W C D$ values were increased in soils treated with low DMP concentration (DMP1 and DMP2), but were significantly decreased in soils treated with higher DMP concentration (DMP3 and DMP4) throughout the incubation period. This meant that 
the total metabolic activity was changed, and indirectly indicated that the soil microbial community was changed by DMP. The functional diversity indices $\left(H^{\prime}, D\right.$, and $\left.E\right)$ of soil microbes can be used to estimate the microbial diversity, dominant microbial diversity and microbial distribution uniformity, respectively. In this study, the microbial distribution uniformity was reduced by DMP with all concentration (DMP 1, DMP2, DMP3, and DMP4), and also the microbial diversity was reduced by higher concentrations (DMP2, DMP3, and DMP4). The dominant microbial diversity appears to have significantly decreased due to the treatment DMP4 compared to CK throughout the incubation period. Similar to our results, Fang et al. (2015) reported changes in the $A W C D$ and diversity indices in atrazine-treated soil. The utilization for different carbon sources reflect metabolic features of soil microbes (Wang et al., 2009). The changes on the utilization of different carbon sources reflect the changes on soil microbial community (Kong et al., 2013; Zhang et al., 2013). The changes on the utilization of different carbon sources (Figure 4) indicated that the metabolic functions of soil microbes were sensitive to DMP contamination, and the metabolic features of soil microbes were changed, which coincided with the results from the $A W C D$ and biodiversity assessments (Figure 3).

Soil enzymes are involved in biological cycling and the development of fertility; thus, they are crucial indicators of soil biochemistry. The activities of soil enzymes are used to estimate the adverse effects of various pollutants on soil health (Masto et al., 2008; Sun et al., 2014) because they are easily affected by the physical, chemical and biological factors of soils (Ma et al., 2015). In this study, the activities of five enzymes were tested, all of them were altered after the treatment of DMP (Figure 5). The activities of catalase, polyphenol oxidase and invertase may reflect the conversion rate of soil organic carbon, while

\section{References}

Allison, S. D. (2012). A trait-based approach for modeling microbial litter decomposition. Ecol. Lett. 15, 1058-1070. doi: 10.1111/j.14610248.2012.01807.x

Amato, K. R., Yeoman, C. J., Kent, A., Righini, N., Carbonero, F., Estrada, A., et al. (2013). Habitat degradation impacts black howler monkey (Alouatta pigra) gastrointestinal microbiomes. ISME J. 7, 1344-1353. doi: 10.1038/ismej.2013.16

Ardley, J. K. (2012). Microvirga lupini sp. nov., Microvirga lotononidis sp. nov. and Microvirga zambiensis sp. nov. are alphaproteobacterial root-nodule bacteria that specifically nodulate and fix nitrogen with geographically and taxonomically separate legume hosts. Int. J. of Syst. Evol. Microbiol. 62, 2579-2588. doi: 10.1099/ijs.0.035097-0

Boonnorat, J., Chiemchaisri, C., Chiemchaisri, W., and Yamamoto, K. (2014). Removals of phenolic compounds and phthalic acid esters in landfill leachate by microbial sludge of two-stage membrane bioreactor. J. Hazard. Mater. 277, 93-101. doi: 10.1016/j.jhazmat.2014.02.044

Bronwyn, D. H., and Raymond, L. C. (1997). Using the Gini coefficient with BIOLOG substrate utilization data to provide an alternative quantitative measure for comparing bacterial soil communities. J. Microbiol. Methods 30, 91-101. doi: 10.1016/S0167-7012(97)00048-1

Caporaso, J. G., Kuczynski, J., Stombaugh, J., Bittinger, K., Bushman, F. D., Costello, E. K., et al. (2010). QIIME allows analysis of highthroughput community sequencing data. Nat. Methods 7, 335-336. doi: 10.1038/nmeth.f.303 the activities of urease and protease may reflect soil nitrogen metabolism (Schloter et al., 2003; Kaplan et al., 2014). The results of soil enzymes suggested that DMP pollution could alter the metabolism of carbon and nitrogen in black soils. These findings were similar to the Illumina-MiSeq sequencing data and the biology-ECO plate analysis results. Therefore, DMP treatments altered the bacterial community and functions in black soils.

\section{Conclusions}

To ensure agricultural sustainability and the normal functioning of soils, it is necessary to maintain the viability and diversity of soil microbe populations. DMP contamination decreased bacterial richness and diversity, changed the bacterial community structure, increased the number of some genera associated with nitrogen metabolism, inhibited the number of other genera that were extremely beneficial to soil health, and disturbed the activities of some enzymes and metabolic functions of the microbes in black soils. These findings propose that DMP causes a direct impact on ecosystem function of black soils.

\section{Acknowledgments}

This study was financially supported by National Natural Science Funds of China (No. 31200390) and Natural Science Funds of Heilongjiang Province in China (No. QC2013C032).

\section{Supplementary Material}

The Supplementary Material for this article can be found online at: http://journal.frontiersin.org/article/10.3389/fmicb. 2015.00405/abstract
Caracciolo, A. B., Bottoni, P., and Grenni, P. (2013). Microcosm studies to evaluate microbial potential to degrade pollutants in soil and water ecosystems. Microchem. J. 107, 126-130. doi: 10.1016/j.microc.2012.05.022

Cartwright, C. D., Thompson, I. P., and Burns, R. G. (2000). Degradation and impact of phthalate plasticizers on soil microbial communities. Environ. Toxicol. Chem. 19, 1253-1261. doi: 10.1002/etc.5620190506

Coelho, M. R. R., Vos, M. D., Carneiro, N. P., Marriel, I. E., Paiva, E., and Seldin, L. (2008). Diversity of nifH gene pools in the rhizosphere of two cultivars of sorghum (Sorghum bicolor) treated with contrasting levels of nitrogen fertilizer. FEMS Microbiol. Lett. 279, 15-22. doi: 10.1111/j.1574-6968.2007.00975.x

Cunliffel, M., and Kertesz, M. A. (2006). Effect of Sphingobium yanoikuyae B1 inoculation on bacterial community dynamics and polycyclic aromatic hydrocarbon degradation in aged and freshly PAH-contaminated soils. Environ. Pollut. 144, 228-237. doi: 10.1016/j.envpol.2005.12.026

Das, S. K., Shome, I., and Guha, A. K. (2012). Biotechnological potential of soil isolate, Flavobacterium mizutaii for removal of azo dyes: kinetics, isotherm, and microscopic study. Sep. Sci. Technol. 47, 1913-1925. doi: 10.1080/01496395.2012.663446

de Gannes, V., Eudoxie, G., and Hickey, W. J. (2013). Prokaryotic successions and diversity in composts as revealed by 454-pyrosequencing. Bioresour. Technol. 133, 573-580. doi: 10.1016/j.biortech.2013.01.138

Dharni, S., Srivastava, A. K., Samad, A., and Patra, D. D. (2014). Impact of plant growth promoting Pseudomonas monteilii PsF84 and Pseudomonas plecoglossicida PsF610 on metal uptake and production of secondary metabolite (monoterpenes) by rose-scented geranium (Pelargonium graveolens 
cv. bourbon) grown on tannery sludge amended soil. Chemosphere 117, 433-439. doi: 10.1016/j.chemosphere.2014.08.001

Drijber, R. A., and McGill, W. B. (1994). Sulfonolipid content of Cytophaga and Flexibacter species isolated from soil and cultured under different nutrient and temperature regimes. Can. J. Microbiol. 40, 132-139. doi: 10.1139/m94-021

Dunlevy, S. R., Singleton, D. R., and Aitken, M. D. (2013). Biostimulation reveals functional redundancy of anthracene-degrading bacteria in polycyclic aromatic hydrocarbon-contaminated soil. Environ. Eng. Sci. 30, 697-705. doi: 10.1089/ees.2013.0067

Erythropel, H. C., Maric, M., and Cooper, D. G. (2012). Designing green plasticizers: influence of molecular geometry on biodegradation and plasticization properties. Chemosphere 86, 759-766. doi: 10.1016/j.chemosphere.2011.10.054

Fang, C., Long, Y., Lu, Y., and Shen, D. (2009). Behavior of dimethyl phthalate (DMP) in simulated landfill bioreactors with different operation modes. Int. Biodeterior. Biodegradation 63, 732-738. doi: 10.1016/j.ibiod.2009.02.011

Fang, H., Lian, J. J., Wang, H. F., Cai, L., and Yu, Y. L. (2015). Exploring bacterial community structure and function associated with atrazine biodegradation in repeatedly treated soils. J. Hazard. Mater. 286, 457-465. doi: 10.1016/j.jhazmat.2015.01.006

Faramarzi, M. A., Fazeli, M., Yazdi, M. T., Adrangi, S., Al-Ahmadi, K. J., Tasharrofi, N., et al. (2009). Optimization of cultural conditions for production of chitinase by a soil isolate of Massilia timonae. Biotechnology 8, 93-99. doi: 10.3923/biotech.2009.93.99

Garland, J. L. (1997). Analysis and interpretation of community level physiological profiles in microbial ecology. FEMS Microbiol. Eco. 24, 289-300. doi: 10.1111/j.1574-6941.1997.tb00446.x

Godoi, I., Sene, L., and Caracciolo, A. B. (2014). Assessment of the bacterial community structure in a Brazilian clay soil treated with atrazine. Ann. Microbiol. 64, 307-311. doi: 10.1007/s13213-013-0665-2

Graham, E. B., Wieder, W. R., Leff, J. W., Weintraub, S. R., Townsend, A. R., Cleveland, C. C., et al. (2014). Do we need to understand microbial communities to predict ecosystem function? A comparison of statistical models of nitrogen cycling processes. Soil Biol. Biochem. 68, 279-282. doi: 10.1016/j.soilbio.2013.08.023

Guan, S. Y. (1986). Soil Enzymes and the Research Method. Beijing: Agricultural Press.

Hanano, A., Ammouneh, H., Almousally, I., Alorr, A., Shaban, M., Alnaser, A. A., et al. (2014). Traceability of polychlorinated dibenzo-dioxins/furans pollutants in soil and their ecotoxicological effects on genetics, functions and composition of bacterial community. Chemosphere 108, 326-333. doi: 10.1016/j.chemosphere.2014.01.061

Hassan, Y. I., Lepp, D., He, J., and Zhou, T. (2014). Draft genome sequences of Devosia sp. strain 17-2-E-8 and Devosia riboflavina strain IFO13584. Genome Announc. 2, e00994-14. doi: 10.1128/genomeA.00994-14

Jin, D. C., Kong, X., Cui, B. J., Bai, Z. H., and Zhang, H. X. (2013). Biodegradation of di-n-butyl phthalate by a newly isolated Halotolerant Sphingobium sp. Int. J. Mol. Sci. 14, 24046-24054. doi: 10.3390/ijms141224046

Jindal, S., Dua, A., and Lal, R. (2013). Sphingopyxis indica sp. nov., isolated from a high dose point hexachlorocyclohexane $(\mathrm{HCH})$-contaminated dumpsite. Int. J. Syst. Evol. Microbiol. 63, 2186-2191. doi: 10.1099/ijs.0.040840-0

Jones, A. M., and Knowles, R. (1991). Enumeration of Flexibacter canadensis in environmental samples by using a bacteriophage isolated from soil. Appl. Environ. Microbiol. 57, 3043-3045.

Juliet, P. M., Lynne, B., and Peter, F. R. (2002). Analysis of microbial community functional diversity using sole-carbon-source utilization profiles: a critique. FEMS Microbiol. Ecol. 42, 1-14. doi: 10.1111/j.1574-6941.2002.tb00990.x

Jurasinski, G., Retzer, V., and Beierkuhnlein, C. (2009). Inventory, differentiation, and proportional diversity: a consistent terminology for quantifying species diversity. Oecologia 159, 15-26. doi: 10.1007/s00442-008-1190-z

Jusselme, M. D., Miambi, E., Mora, P., Diouf, M., and Rouland-Lefèvre, C. (2013). Increased lead availability and enzyme activities in root-adhering soil of Lantana camara during phytoextraction in the presence of earthworms. Sci. Total Environ. 445-446, 101-109. doi: 10.1016/j.scitotenv.2012.12.054

Kaplan, H., Ratering, S., Hanauer, T., Felix-Henningsen, P., and Schnell, S. (2014). Impact of trace metal contamination and in situ remediation on microbial diversity and respiratory activity of heavily polluted Kastanozems. Biol. Fertil. Soils 50:735-744. doi: 10.1007/s00374-013-0890-7
Kolton, M., Frenke, O., Elad, Y., and Cytryn, E. (2014). Potential role of Flavobacterial gliding-motility and type IX secretion system complex in root colonization and plant defense. Mol. Plant Microbe. Interact. 27, 1005-1013. doi: 10.1094/MPMI-03-14-0067-R

Kong, X., Wang, C., and Ji, M. (2013). Analysis of microbial metabolic characteristics in mesophilic and thermophilic biofilters using Biolog plate technique. Chem. Eng. J. 230, 415-421. doi: 10.1016/j.cej.2013.06.073

Kuczynski, J., Lauber, C. L., Walters, W. A., Parfrey, L. W., Clemente, J. C., Gevers, D., et al. (2012). Experimental and analytical tools for studying the human microbiome. Nat. Rev. Genet. 13, 47-58. doi: 10.1038/nrg3129

Kunin, V., Engelbrektson, A., Ochman, H., and Hugenholtz, P. (2010). Wrinkles in the rare biosphere: pyrosequencing errors can lead to artificial inflation of diversity estimates. Environ. Microbiol. 12, 118-123. doi: 10.1111/j.14622920.2009.02051.x

Ladd, J. N., and Butler, J. H. A. (1972). Short-term assays of soil proteolytic enzyme activities using proteins and dipeptide derivatives as substrates. Soil Biol. Biochem. 4, 19-30. doi: 10.1016/0038-0717(72)90038-7

Latini, G. (2005). Monitoring phthalate exposure in humans. Clin. Chim. Acta 361, 20-29. doi: 10.1016/j.cccn.2005.05.003

Liu, J. J., Sui, Y. Y., Yu, Z. H., Shi, Y., Chu, H. Y., Jin, J., et al. (2014a). High throughput sequencing analysis of biogeographical distribution of bacterial communities in the black soils of northeast China. Soil Biol. Biochem. 70, 113-122. doi: 10.1016/j.soilbio.2013.12.014

Liu, L., Li, T. Y., Wei, X. H., Jiang, B. K., and Fang, P. (2014b). Effects of a nutrient additive on the density of functional bacteria and the microbial community structure of bioorganic fertilizer. Bioresour. Technol. 172, 328-334. doi: 10.1016/j.biortech.2014.08.125

Lozupone, C., and Knight, R. (2005). UniFrac: a new phylogenetic method for comparing microbial communities. Appl. Environ. Microbiol. 71, 8228-8235. doi: 10.1128/AEM.71.12.8228-8235.2005

Ma, S. C., Zhang, H. B., Ma, S. T., Wang, R., Wang, G. X., Shao, Y., et al. (2015). Effects of mine wastewater irrigation on activities of soil enzymes and physiological properties, heavy metal uptake and grain yield in winter wheat. Ecotoxicol. Environ. Saf. 113, 483-490. doi: 10.1016/j.ecoenv.2014. 12.031

Masto, R. E., Chhonkar, P. K., Singh, D., and Patra, A. K. (2008). Changes in soil quality indicators under long-term sewage irrigation in a sub-tropical environment. Environ. Geol. 38, 1577-1582. doi: 10.1007/s00254-008-1223-2

Peiffer, J. A., Spor, A., Koren, O., Jin, Z., Tringe, S. G., Dangl, J. L., et al. (2013). Diversity and heritability of the maize rhizosphere microbiome under field conditions. Proc. Natl. Acad. Sci. U.S.A. 110, 6548-6553. doi: $10.1073 /$ pnas. 1302837110

Prasad, B., and Suresh, S. (2015). Biodegradation of dimethyl phthalate ester using free cells, entrapped cells of Variovorax sp. BS1 and cell free enzyme extracts: a comparative study. Int. Biodeter. Biodegr. 97, 179-187. doi: 10.1016/j.ibiod,.2014.11.004

Raina, V., Suar, M., Singh, A., Prakash, O., Dadhwal, M., Gupta, S. K., et al. (2008). Enhanced biodegradation of hexachlorocyclohexane $(\mathrm{HCH})$ in contaminated soils via inoculation with Sphingobium indicum B90A. Biodegradation 19, 27-40. doi: 10.1007/s10532-007-9112-z

R Development Core Team. (2008). R: A Language and Environment for Statistical Computing. Vienna: $\mathrm{R}$ foundation for statistical computing.

Rivas, R., Velázquez, E., Willems, A., Vizcaíno, N., Subba-Rao, N. S., Mateos, P. F., et al. (2002). A new species of Devosia that forms a unique nitrogen-fixing rootnodule symbiosis with the aquatic legume Neptunia natans (L.f.) Druce. Appl. Environ. Microbiol. 68, 5217-5222. doi: 10.1128/AEM.68.11.5217-5222.2002

Ryu, S. H., Chung, B. S., Le, N. T., Jang, H. H., Yun, P. Y., Park, W., et al. (2008). Devosia geojensis sp. nov., isolated from diesel-contaminated soil in Korea. Int. J. Syst. Evol. Microbiol. 58, 633-636. doi: 10.1099/ijs.0.65481-0

Saiya-Cork, K. R., Sinsabaugh, R. L., and Zak, D. R. (2002). The effects of long term nitrogen deposition on extracellular enzyme activity in an Acer saccharum forest soil. Soil Biol. Biochem. 34, 1309-1315. doi: 10.1016/S00380717(02)00074-3

Sala, M. M., Pinhassi, J., and Gasol, J. M. (2006). Estimation of bacterial use of dissolved organic nitrogen compounds in aquatic ecosystems using Biolog plates. Aquat. Microb. Ecol. 42, 1-5. doi: 10.3354/ame042001

Saxena, A., Anand, S., Dua, A., Sangwan, N., Khan, F., and Lal, R. (2013). Novosphingobium lindaniclasticum sp. nov., a hexachlorocyclohexane 
( $\mathrm{HCH})$-degrading bacterium isolated from an $\mathrm{HCH}$ dumpsite. Int. J. Syst. Evol. Microbiol. 63, 2160-2167. doi: 10.1099/ijs.0.045443-0

Schloss, P. D., Westcott, S. L., Ryabin, T., Hall, J. R., Hartmann, M., Hollister, E. B., et al. (2009). Introducing mothur: opensource, platformindependent, community-supported software for describing and comparing microbial communities. Appl. Environ. Microbiol. 75, 7537-7541. doi: 10.1128/AEM.01541-09

Schloter, M., Dilly, O., and Munch, J. C. (2003). Indicators for evaluating soil quality. Agric. Ecosyst. Environ. 98, 255-262. doi: 10.1016/S01678809(03)00085-9

Singh, J. S. (2015). Microbes: the chief ecological engineers in reinstating equilibrium in degraded ecosystems. Agric. Ecosyst. Environ. 203, 80-82. doi: 10.1016/j.agee.2015.01.026

Souza, F. L., Aquino, J. M., Irikura, K., Miwa, D. W., Rodrigo, M. A., and Motheo, A. J. (2014). Electrochemical degradation of the dimethyl phthalate ester on a fluoride-doped $\mathrm{Ti} / \beta-\mathrm{PbO}_{2}$ anode. Chemosphere $109,187-194$. doi: 10.1016/j.chemosphere.2014.02.018

Stelting, S. A., Burns, R. G., Sunnac, A., and Buntd, C. R. (2014). Survival in sterile soil and atrazine degradation of Pseudomonas sp. strain ADP immobilized on zeolite. Bioremediat. J. 18, 309-316. doi: 10.1080/10889868.2014.938723

Sun, J., Zhang, Q., Zhou, J., and Wei, Q. P. (2014). Illumina amplicon sequencing of $16 \mathrm{~S}$ rRNA tag reveals bacterial community development in the rhizosphere of apple nurseries at a replant disease site and a new planting site. PLoS ONE 9:e111744. doi: 10.1371/journal.pone.0111744

Troxler, J., Svercel, M., Natsch, A., Zala, M., Keel, C., Moënne-Loccoz, Y., et al. (2012). Persistence of a biocontrol Pseudomonas inoculant as high populations of culturable and non-culturable cells in 200-cm-deep soil profiles. Soil Biol. Biochem. 44, 122-129. doi: 10.1016/j.soilbio.2011.09.020

Wang, C., Xi, J. Y., Hu, H. Y., and Yao, Y. (2009). Effect of UV pretreatment on microbial community structure and metabolic characteristics in a subsequent biofilter treating gaseous chlorobenzene. Bioresour. Technol. 100, 5581-5587. doi: 10.1016/j.biortech.2009.05.074

Wang, Y. D., Feng, N. N., Li, T. X., Zhang, X. Z., and Liao, G. T. (2008). Spatial variability of soil cation exchange capacity in hilly tea plantation soils under different sampling scales. Agric. Sci. China 7, 96-103. doi: 10.1016/S16712927(08)60027-9

Wang, Z., Deng, D. Y., and Yang, L. L. (2014). Degradation of dimethyl phthalate in solutions and soil slurries by persulfate at ambient temperature. J. Hazard. Mater. 271, 202-209. doi: 10.1016/j.jhazmat.2014.02.027

Wu, X. H., Xu, J., Dong, F. S., Liu, X. G., and Zheng, Y. Q. (2014). Responses of soil microbial community to different concentration of fomesafen. J. Hazard. Mater. 273, 155-164. doi: 10.1016/j.jhazmat.2014.03.041
Xu, X. Z., Xu, Y., Chen, S. C., Xu, S. G., and Zhang, H. W. (2010). Soil loss and conservation in the black soil region of northeast China: a retrospective study. Environ. Sci. Policy 13, 793-800. doi: 10.1016/j.envsci.2010. 07.004

Yan, Q. X., Hong, Q., Han, P., Dong, X. J., Shen, Y. J., and Li, S. P. (2007). Isolation and characterization of a carbofuran-degrading strain Novosphingobium sp. FND-3. FEMS Microbiol. Lett. 271, 207-213. doi: 10.1111/j.1574-6968.2007.00718.x

Yang, H. F., Yan, M., Yao, J., Wang, Y. B., and Liu, D. Y. (2007). Impact of Cu and Zn pollution on rape growth and soil enzyme activity. Chin. J. Appl. Ecol. 18, 1484-1490.

Yang, W. H., Zhang, T. X., Li, S. L., and Ni, W. Z. (2014). Metal removal from and microbial property improvement of a multiple heavy metals contaminated soil by phytoextraction with a cadmium hyper accumulator Sedum alfrediiH. J. Soil Sediment. 14, 1385-1396. doi: 10.1007/s11368-014-0875-7

Yousuf, B., Kumar, R., Mishra, A., and Jha, B. (2014). Differential distribution and abundance of diazotrophic bacterial communities across different soil niches using a gene-targeted clone library approach. FEMS Microbiol. Lett. 360, 117-125. doi: 10.1111/1574-6968.12593

Zhang, H. F., Li, G., Song, X. L., Yang, D. L., Li, Y. J., Qiao, J., et al. (2013). Changes in soil microbial functional diversity under different vegetation restoration patterns for Hulunbeier Sandy Land. Acta Ecol. Sin. 33, 38-44. doi: 10.1016/j.chnaes.2012.12.006

Zhang, W., Wang, H., Zhang, R., Yu, X. Z., Qian, P. Y., and Wong, M. H. (2010). Bacterial communities in PAH contaminated soilsat an electronic-waste processing center in China. Ecotoxicology 19, 96-104. doi: 10.1007/s10646-0090393-3

Zhang, Y., Wang, P. J., Wang, L., Sun, G. Q., Zhao, J. Y., Hui Zhang, H., et al. (2015). The influence of facility agriculture production on phthatate esters distribution in black soils of northeast China. Sci. Total Environ. 506-507, 118-125. doi: 10.1016/j.scitotenv.2014.10.075

Conflict of Interest Statement: The author declares that the research was conducted in the absence of any commercial or financial relationships that could be construed as a potential conflict of interest.

Copyright (C) 2015 Wang, Hu, Xu, Liu, Hu and Zhang. This is an open-access article distributed under the terms of the Creative Commons Attribution License (CC BY). The use, distribution or reproduction in other forums is permitted, provided the original author(s) or licensor are credited and that the original publication in this journal is cited, in accordance with accepted academic practice. No use, distribution or reproduction is permitted which does not comply with these terms. 